\title{
Consensus Recommendations on the Use of a Fractional Radiofrequency Microneedle and Its Applications in Dermatologic Laser Surgery
}

Seung Jae Lee', Un-Cheol Yeo² Seong Ho Wee ${ }^{3}$, Jae Hong Shim ${ }^{4}$ Kee-Young Roh', Ee Seok Lim ${ }^{5}$ Chun Pill Choi ${ }^{6}$, Suk Bae Seo ${ }^{7}$ Geun-Soo Lee ${ }^{8}$, Tae-Heung Kim ${ }^{9}$ Won-Serk Kim ${ }^{1}$

\footnotetext{
${ }^{1}$ Department of Dermatology, Kangbuk Samsung Hospital, Sungkyunkwan University School of Medicine, Seoul, Korea

${ }^{2}$ S\&U Dermatologic Clinic, Seoul, Korea ${ }^{3}$ Dr. Wee's Dermatological Clinic, Seoul, Korea ${ }^{4}$ CNP Dermatologic Clinic, Seoul, Korea

${ }^{5}$ Lim ee seok Thema Dermatologic Clinic, Seoul, Korea

${ }^{6}$ Skyfeel Dermatologic Clinic, Seoul, Korea ${ }^{7}$ SAS Dermatologic Clinic, Seoul, Korea

${ }^{8}$ Srs. Woo \& Hann's Skin \& Laser Center, Seoul, Korea

${ }^{9}$ White-Line Skin Clinic \& Research Center, Changwon, Korea
}

Received December 13, 2013

Reviced January 7, 2014

Accepted January 8, 2014

\section{Correspondence}

Won-Serk Kim

Department of Dermatology, Kangbuk Samsung Hospital, Sungkyunkwan University School of Medicine, 108, Pyeong-dong, Jongno-gu,

Seoul 110-746, Korea

Tel: +82-2-2001-2228

Fax: +82-2-2001-2236

E-mail: susinianaver.com

(C) Korean Society for Laser Medicine and Surgery

(c) This is an open access article distributed under the terms of the Creative Commons Attribution NonCommercial License (http://creativecommons.org/ licenses/by-nc/3.0) which permits unrestricted noncommercial use, distribution, and reproduction in any medium, provided the original work is properly cited.

\section{Background and Objectives}

Fractional radiofrequency micro-needle (FRM) has revolutionized the way we treat a variety of cutaneous conditions using radiofrequency technology. A comprehensive guide is required for clinicians using this technology in treatment of a variety of skin conditions in various skin types.

\section{Materials and Methods}

The guidelines were made from a recent round table discussion among experienced clinicians and a review of recent medical literature.

\section{Results}

We concluded that FRM is a safe and effective modality for treatment of conditions commonly encountered in dermatology, and recommended guidelines for optimal treatment of several skin conditions on and off the face using FRM.

\section{Conclusion}

We developed reproducible guidelines for most effective treatment of a variety of skin conditions using FRM. Conduct of large, multicenter trials will be needed for further optimization of treatment parameters.

\section{Key words}

Consensus; Fractional; Radiofrequency; Micro-needle 


\section{INTRODUCTION}

Radiofrequency (RF) energy is widely used in various medical fields. In dermatological field, RF devices have many aesthetic applications, including skin lifting and tightening, body contouring and cellulite reduction. ${ }^{1-3}$ Recently, combining the fractional technique with a classical nonablative radiofrequency device has been introduced and revolutionized the field of skin rejuvenation. ${ }^{1.4-7}$

Fractional radiofrequency micro-needle (FRM) system delivers an exact amount of RF energy at accurate depth directly into the deep dermal area through micro-needle. ${ }^{1,4-7}$

Although the use of FRM device has been examined and expanded by some clinicians, the exact parameters and guidelines have not been established. In this article, concrete treatment recommendations for different dermatologic conditions and suitable techniques for pre- and after-treatment will be discussed. Expert dermatologists have met to discuss how to make the best use of the FRM devices (INTRAcel; Jeisys, Seoul, Korea) for various indications and suggest optimal guidelines.

\section{HISTORY OF RADIOFREOUENCY}

RF devices are commonly used in our life (Radio, TV broadcasting, wireless internet and phones, microwaves, satellite communications, and so on). ${ }^{3,8-10}$ In the medical field, RF energy has been used for over 80 years. ${ }^{2,11}$ The initial application of RF to medicine was electrocautery in 1920s, but now RF is widely used for many medical conditions, ranging from surgery for minimal invasive technique to aesthetic procedures. ${ }^{2,11-15}$

\section{RADIOFREQUENCY}

Radiofrequency (RF) is a rate of oscillation in the range of about $3 \mathrm{kHz}$ to $300 \mathrm{GHz} .{ }^{8-10} \mathrm{RF}$ devices generate electrical current using electromagnetic radiation., 2,10 When the current is applied to tissue, it encounters resistance, which is an inherent property of the particular tissue, also called as impedance., 210,16 This generates heat energy. ${ }^{2,10,16}$ Namely, thermal heat energy is generated by transfer of energy from the electrical field to the charged particles in the target tissue. ${ }^{16,17}$ The energy output is calculated using the following formula: Energy $(J)=I^{2} \times z \times t$, Where $I$ is current, $z$ is impedance, and $t$ is time in second. Therefore, Heat energy $(\mathrm{J})$ is created by impedance ( $z$ ) to the movement of electrons relative to the amount of currents ( $/$ ) and time that current is delivered to tissue. ${ }^{1,3,10}$ The parts of the body with high blood content have the lowest impedance, namely highest electrical conductivity. ${ }^{1,3,18}$ Bone, for example, has very high impedance and consequently the electrical current cannot penetrate the bone tissue, so the current flows around it. ${ }^{3,10,11}$ In skin, dry skin has high impedance, so in order to enhance electrical current, hydration is necessary. 2,3,10

Contrary to laser light which can be scattered and absorbed before reaching the target tissue, RF energy is not affected by tissue diffraction and chromophore absorption. ${ }^{2,15}$ Therefore amount of RF energy is more controllable than laser light and it can be applied to any type of skin. ${ }^{1,2,16}$

\section{MONOPOLAR AND BIPOLAR RF}

Monopolar RF current is applied between a single electrode tip and a grounding plate, so the current goes through the patient to complete the current cycle. ${ }^{2,3}$ On the other hand, bipolar RF current is applied between two points on the tip of a probe so the current only goes through the tissue between the two electrodes of the instrument. ${ }^{2,3}$ The main advantage of monopolar system is that it can achieve high penetration of emitted current. ${ }^{1-3,19}$ The bipolar RF system has its limitations on treating deeper skin area, but it provides more controlled distribution of energy. ${ }^{1-3,20}$

\section{FRACTIONAL RF}

Fractional RF is combination of fractional technique with a classical nonablative radiofrequency. ${ }^{6,7}$ Hantash et al. introduced a minimally invasive device, microneedle fractional RF, which adopted microneedle therapy system (MTS) for delivering bipolar RF energy directly into the skin through microneedle. ${ }^{4}$ It generates fractional radiofrequency thermal zone (RFTZ) within the reticular dermis. ${ }^{4}$ The FRM system is a minimally invasive nonablative RF device that delivers mono-and bipolar RF energy in the form of an electrical current that generates heat through the inherent electrical resistance of dermal and subcutaneous tissue. .,20 $^{2}$

\section{Device properties}

One of FRM system, INTRAcel, consists of a handheld applicator with a disposable single-use treatment tip. The tip contains 49 micro-needle electrodes in $1 \mathrm{~cm}^{2}$ area. The micro-needle electrodes are nonconductive except for the tip, beginning $0.3 \mathrm{~mm}$ form the distal end, in order 
to protect from radiofrequency heating at the insertion site. Needle length can be adjusted $10.5 \mathrm{~mm}, 0.8 \mathrm{~mm}$, $1.5 \mathrm{~mm}, 2.0 \mathrm{~mm}$ ) for various clinical situations. Needles automatically are inserted into the skin vertically, and RF is emitted 0.2 seconds after inserting the needles for safety. The amount of RF emission differs according to the energy levels. The superficial RF rejuvenation (SRR) tip makes superficial ablation which may synergistic effects if combined with microneedle tips.

\section{Mechanism of action}

The RF energy is fractionally delivered by MTS and it creates RFTZ. ${ }^{520}$ Fractional thermal injury of dermal collagen induces a vigorous wound healing process leading to inflammatory cascade and stimulates new collagen, elastin, and hyaluronic acid formation, eventually resulting in dermal remodeling. ${ }^{5,20}$ Furthermore, skin needling with microneedles has been reported to stimulate migration and proliferation of keratinocytes and fibroblasts by inducing the release of several growth factors. ${ }^{5,20,21}$ And, untreated areas which are located between treated areas serve as a reservoir of cells that promote and accelerate wound healing. ${ }^{20,21}$

\section{Histologic and ultra-structural changes}

Lim et al. histologically evaluated pig skin up to 10 weeks after FRM treatment, using energies from 1.25 to $6.25 \mathrm{~J} / \mathrm{cm}^{2}$. Examination post-treatment biopsy revealed that thermally coagulated zone was localized in the reticular dermis without damaging the epidermis. After 10 weeks, the coagulation necrosis zone was replaced by new collagen tissue in H\&E staining. And RT-PCR studies indicated an increase in heat shock protein, matrix metalloproteinase and extracellular matrix protein. Increased collagen expressions after treatment support the notion that the thermal injury created by the RF device may stimulate a wound healing response.

Table 1. Fractional radiofrequency micro-needle (FRM) treatment level guidelines for skin rejuvenation - face ${ }^{21}$

\begin{tabular}{|c|c|c|c|c|c|c|c|c|}
\hline \multicolumn{3}{|c|}{ Condition } & Option & $\begin{array}{l}\text { Needle depth/ } \\
\text { bi-mono }\end{array}$ & Energy level (L) & Pass & Interval & Comment \\
\hline \multirow[t]{20}{*}{ Rejuvenation } & \multirow{3}{*}{\multicolumn{2}{|c|}{ Eyes (periorbital) }} & option 1 & 0.5bipolar (B) & 4 & 1 & 4-6 weeks & \\
\hline & & & & 0.5 monopolar (M) & 6 & 1 & & \\
\hline & & & option 2 & $\begin{array}{l}\text { Superficial RF reju- } \\
\text { venation (SRR) }\end{array}$ & 5,6 & 1 & & $\begin{array}{l}\text { L6 with significant down time. } \\
\text { Stacking application is recommended for } \\
\text { beginners. }\end{array}$ \\
\hline & \multirow{2}{*}{\multicolumn{2}{|c|}{ Forehead }} & & $0.5 \mathrm{~B}$ & 4 & 1 & & \\
\hline & & & & $0.8 \mathrm{~B}$ & 4 & 1 & & \\
\hline & \multirow{3}{*}{\multicolumn{2}{|c|}{ Cheek }} & & $0.8 \mathrm{~B}$ & 4 & 1 & & \multirow{3}{*}{$\begin{array}{l}\text { From midway neck in vector over cheek } \\
\text { (care if slight build) }\end{array}$} \\
\hline & & & & $0.8 \mathrm{M}$ & 6 & 1 & & \\
\hline & & & & $1.5 \mathrm{~B}$ & 4 & 1 & & \\
\hline & \multirow{2}{*}{\multicolumn{2}{|c|}{ Neck }} & & $0.5 \mathrm{~B}$ & 4 & 1 & & \multirow{4}{*}{$\begin{array}{l}\text { No overlap } \\
\text { Manual states Depth: 0.8-1.5 mm }\end{array}$} \\
\hline & & & & $0.8 \mathrm{~B}$ & 4 & 1 & & \\
\hline & \multirow{2}{*}{\multicolumn{2}{|c|}{ Lip (Peri-Oral) }} & & $0.5 \mathrm{~B}$ & 4 & 1 & & \\
\hline & & & & $0.5 \mathrm{M}$ & 6 & 1 & & \\
\hline & \multirow{2}{*}{\multicolumn{2}{|c|}{ Nose }} & & $0.8 \mathrm{~B}$ & 4 & 1 & & \multirow{2}{*}{$\begin{array}{l}\text { Ala part is recommended } 1.5 \mathrm{~B} / \mathrm{L} 6,0.5 \mathrm{~B} \text { has } \\
\text { risk of shallow treatment }\end{array}$} \\
\hline & & & & $0.5 \mathrm{~B}$ & 4 & 1 & & \\
\hline & \multirow{6}{*}{$\begin{array}{c}\text { Specific } \\
\text { Zone }\end{array}$} & \multirow[t]{2}{*}{ Crow's feet } & & $0.5 \mathrm{~B}, 0.8 \mathrm{~B}$ & 3,4 & 2 & & \multirow{2}{*}{$\begin{array}{l}\text { Vectoring pattern is optional as per per- } \\
\text { sonal choice of operator }\end{array}$} \\
\hline & & & & SRR & & 1 & & \\
\hline & & \multirow{2}{*}{$\begin{array}{l}\text { Perioral } \\
\text { rhytids }\end{array}$} & & $0.5-0.8 \mathrm{~B}$ & 3,4 & 2 & & \multirow{2}{*}{$\begin{array}{l}\text { Vectoring pattern is optional as per per- } \\
\text { sonal choice of operator }\end{array}$} \\
\hline & & & & SRR & & 1 & & \\
\hline & & \multirow[t]{2}{*}{$\begin{array}{l}\text { Nasolabial } \\
\text { folds }\end{array}$} & & \multirow[t]{2}{*}{$1.5 \mathrm{~B}$} & \multirow[t]{2}{*}{5,6} & \multirow[t]{2}{*}{2} & & $\begin{array}{l}\text { Vectoring pattern is optional as per per- } \\
\text { sonal choice of operator. }\end{array}$ \\
\hline & & & & & & & & $\begin{array}{l}\text { For stronger results, } 20 \% \text { overlap treatment } \\
\text { directed for unmovable anchoring areas } \\
\text { can get better results, and NAR treatment } \\
\text { after it, also make better result. }\end{array}$ \\
\hline \multirow{4}{*}{\multicolumn{3}{|c|}{$\begin{array}{l}\text { For intensive rejuvenation for very } \\
\text { photo damaged skin on cheeks and } \\
\text { neck }\end{array}$}} & & 1.5 & 5,6 & 1 & & \multirow{4}{*}{$\begin{array}{l}\text { It does not make any difference if monopo- } \\
\text { lar or bipolar first }\end{array}$} \\
\hline & & & & 0.8 & 3,4 & 1 & & \\
\hline & & & & 0.5 & 3,4 & 1 & & \\
\hline & & & & $2 \mathrm{M}$ & 6,7 & 1 & & \\
\hline
\end{tabular}




\section{Application}

1) Skin rejuvenation

Seo et al. studied FRM system on facial rejuvenation of twenty five healthy women with ages ranging from 41 to 64 years, with moderate to severe wrinkles and sagging skin. ${ }^{22}$ All patients received three sessions of treatments every 4 weeks. The energy levels were determined based on the specific anatomical location and proximity of underlying bones. The treatment depths were altered according to underlying skin thickness (periorbital area: $0.5 \mathrm{~mm}$, forehead: $0.8 \mathrm{~mm}$, chin and temple: $1.0 \mathrm{~mm}$, and cheek: $2.0 \mathrm{~mm}$ ). All patients showed clinical improvement on wrinkle, skin laxity and skin texture and side effects were minimal and well tolerable. ${ }^{21}$

Consensus panel members agreed that FRM system will not replace standard surgical treatment such as rhytidectomy. However, FRM system may play a major role in the cosmetic improvement of early skin laxity and be preferred by patients who wish to avoid surgery for the fear of its associated risk of complications. And, the panel suggested FRM system would be well combined with other nonsurgical approaches such as Botox, filler agents, and other nonablative laser treatments. The panel members suggested proper parameters based on specific anatomical areas such as forehead, periorbital area, nose, décolletage and dorsum of hands which are shown on Table 1 and 2.

\section{2) Acne scar, enlarged pore and traumatic scar}

As FRM treatment appears to be related to dermal matrix regeneration, it may be one of the effective treatment option for improving acne scars and facial pores. A study of the FRM system on thirty patients with acne scar and large facial pores revealed that the grade of acne scars, investigator global assessment of large pores, skin surface roughness, dermal density, and microscopic and composite image improved after two sessions of treatment. ${ }^{20}$ Consensus panel members agreed that FRM system could be an ideal treatment option for acne scar as well as other surgical and traumatic scar. Suggested proper parameters by panel are shown on Table 3 .

Table 2. FRM treatment level guidelines for skin rejuvenation - body

\begin{tabular}{|c|c|c|c|c|c|c|}
\hline Condition & Option & Needle depth/bi-mono & Energy level & Pass & Interval & Comment \\
\hline \multirow[t]{2}{*}{ Decolletage } & & $1.5 \mathrm{~B}$ & & $2-3$ & 6 weeks & \\
\hline & & $0.8 \mathrm{~B}$ & 4 & 2 & & \\
\hline \multirow[t]{2}{*}{ Hand rejuvenation } & & $0.8 \mathrm{~B}$ & 4 & 1 & & \\
\hline & & $0.5 \mathrm{~B}$ & 4 & 1 & & \\
\hline \multirow[t]{2}{*}{ Telangiectasia } & & $0.5 B$ & 3 & $1-2$ & & \\
\hline & & $0.8 \mathrm{~B}$ & 4 & 1 & & \\
\hline
\end{tabular}

Table 3. FRM treatment level guidelines for acne scar, enlarged pore and traumatic $\mathrm{scar}^{20}$

\begin{tabular}{|c|c|c|c|c|c|c|c|}
\hline \multicolumn{2}{|c|}{ Condition } & Option & \multirow{2}{*}{$\begin{array}{c}\text { Needle depth/ } \\
\text { bi-mono } \\
0.5 \mathrm{~B}\end{array}$} & \multirow{2}{*}{$\begin{array}{c}\text { Energy level } \\
5\end{array}$} & \multirow{2}{*}{$\begin{array}{r}\text { Pass } \\
1,2\end{array}$} & \multirow{2}{*}{$\begin{array}{c}\text { Interval } \\
\text { 4-6 weeks }\end{array}$} & \multirow{3}{*}{$\begin{array}{l}\text { Comment } \\
\mathrm{L} 50.8 \times 2 \text { passes and } \mathrm{L} 50.5 \times 2 \text { passes } \\
\text { gets great results. } \\
\text { In case of deep treatment, }(1.5,2.0 \mathrm{~mm} \\
+\mathrm{L} 5,6,7) \text {; nerve block recommended. }\end{array}$} \\
\hline Pore treatments & Cheek & & & & & & \\
\hline & & & $0.8 \mathrm{~B}$ & 5 & 1,2 & & \\
\hline & nose (ala area) & & $1.5 \mathrm{~B}$ & 6 & 1 & & \\
\hline & & & $0.8 \mathrm{~B}$ & 4,5 & 1,2 & & \\
\hline & glabella & & $0.8 \mathrm{~B}$ & 4 & 1 & & \\
\hline & & & $0.5 \mathrm{~B}$ & 4 & 1 & & \\
\hline & mentum & & $0.5 \mathrm{~B}$ & 4 & 1 & & \\
\hline & & & $0.8 \mathrm{~B}$ & 4 & 1 & & \\
\hline \multirow{3}{*}{\multicolumn{2}{|c|}{ Acne scarring Cheeks }} & & $0.5 B$ & 4 & 1 & & \\
\hline & & & $0.8 \mathrm{~B}$ & 4,5 & 1 & & \\
\hline & & & $1.5 \mathrm{~B}$ & $4,5,6$ & $1-2$ & & \\
\hline \multirow{2}{*}{\multicolumn{2}{|c|}{$\begin{array}{l}\text { Acne scarring on body areas, backs, } \\
\text { arms etc }\end{array}$}} & & $0.5 B$ & 5 & $1-2$ & & \\
\hline & & & $0.8 \mathrm{~B}$ & 5 & $1-2$ & & \\
\hline \multirow{2}{*}{\multicolumn{2}{|c|}{ Traumatic scars }} & & $0.5-2 \mathrm{~B}$ & 4 & $2-3$ & & Levels depends on depth \\
\hline & & & $0.8 \mathrm{~B}$ & 4 & $1-2$ & & \\
\hline
\end{tabular}


3) Acne vulgaris

FRM devices have been used to treat acne vulgaris. ${ }^{22,23}$ A study of the FRM system on 20 patients with moderate inflammatory acne revealed clinical improvement as evidenced by a reduction in lesion count and reduction sebum secretion. ${ }^{23}$ Side effects included temporary erythema, tingling, and burning sensation after treatment, but resolved in 2 days after the treatment. The panel contended that FRM treatment helped in decreasing inflammatory acne lesion and sebum secretion and suggested proper parameters shown on Table 4.

\section{4) Striae distensae/atrophic scar}

Striae distensae are atrophic dermal scars with overlying epidermal atrophy that may cause significant cosmetic problems. Although a variety of laser and light sources have been used for the treatment of striae distensae, to date no definite 'gold standard' treatment modality has been determined. ${ }^{24-26} \mathrm{~A}$ study of the FRM system on 30 female patients with moderate to severe striae distensae showed optimal clinical results with minimal side effects. ${ }^{25}$ The panel contended that FRM system could be one of the suitable options for treating striae distensae and atrophic scar and suggested proper parameters which are shown on Table 5.

\section{Pretreatment regimens}

Right before the treatment, the face needs to be cleaned with facial foam cleanser and 70\% alcohol. Patients with a history of herpes simplex may be given Valacyclovir 2 g orally every 12 hours on the day of treatment. Some suggest that all patients take pretreatment Valacyclovir because the treatment with FRM has triggered herpetic outbreaks in patients with no known history of the condition. For anesthesia, physicians recommend a topical anesthetic applied one hour before the procedure to an area no greater than 300 to $400 \mathrm{~cm}^{2}$ and removal of the topical anesthesia before the treatment.

\section{Post treatment care}

After treatment, the patient needs to avoid washing his or her face for one day and is advised to apply topical antibiotic application for two to three days after the treatment. The panel advised that patients avoid prolonged exposure to direct sunlight and apply sunscreen with SPF30 or greater. Recently, to decrease the intensity and duration of post-treatment erythema, light-emitting diode treatment has been performed immediately after FRM treatment.

\section{Side effect}

Common side effects were mild pain and temporary erythema during and after procedures. In general, incidence of side effects of FRM treatment is lower than conventional fractionated lasers. And the risk of postinflammatory hyperpigmentation is minimal, and if it occurs, it usually resolves within 4 weeks. There might be some vesiculation and superficial burn after treatment, but mostly it is attributed to uneven electrode contact to skin. In area such as forehead and temple where underlying bones are close to the skin surface and applying high RF energy could be dangerous, clinicians must lower RF energy and depth of the needle. There were no reports of infection or scarring from any of the patients of the panel. The panel advised that clinicians must use appropriate parameters, including energy level needle depth according to the cosmetic units of the face. The panel also emphasized that proper contact of electrode to skin surface is important to reduce adverse event.

\section{Conclusion}

Consensus panel members agreed that FRM system

Table 4. FRM treatment level guidelines for active acne $\mathrm{e}^{22,23}$

\begin{tabular}{|c|c|c|c|c|c|c|}
\hline Condition & Option & Needle depth/bi-mono & Energy level & Pass & Interval & Comment \\
\hline \multirow[t]{2}{*}{ Active acne } & & $0.8 \mathrm{~B}$ & 4 & 1 & 4-6 weeks & Avoid treating severe inflammatory acne \\
\hline & & $1.5 B$ & 4 & 1,2 & & \\
\hline
\end{tabular}

Table 5. FRM treatment level guidelines for striae distensae and atrophic scar ${ }^{24-26}$

\begin{tabular}{|c|c|c|c|c|c|c|}
\hline Condition & Option & Needle depth/bi-mono & Energy level & Pass & Interval & Comment \\
\hline Stretch marks & & $0.8 \mathrm{~B}$ & 4 & 1 & 6 weeks & Levels depends on depth. \\
\hline Atrophic thin scar & & $1.5 \mathrm{~B}$ & 4,5 & 1 & & $\begin{array}{l}\text { Sometimes, in a case of fragile thin scar, } \\
\text { SRR treatment can be considered. }\end{array}$ \\
\hline
\end{tabular}


could provide a viable, minimally invasive treatment alternative for skin conditions commonly encountered in the dermatology practice. And they developed reproducible parameters and guidelines in order to most effectively treat a variety of skin conditions using FRM device. However, for beginners, it is recommended one level down of this guidline, and auto mode minimally $0.65-$ 0.8 s when use level 5 or 6 . Large, multicenter trials are needed for further optimization of treatment parameters and guidelines.

\section{REFERENCES}

1. Lolis MS, Goldberg DJ. Radiofrequency in cosmetic dermatology: a review. Dermatol Surg 2012;38:1765-76.

2. Alster TS, Lupton JR. Nonablative cutaneous remodeling using radiofrequency devices. Clin Dermatol 2007;25:487-91.

3. Belenky I, Margulis A, Elman M, Bar-Yosef U, Paun SD. Exploring channeling optimized radiofrequency energy: a review of radiofrequency history and applications in esthetic fields. Adv Ther 2012;29:249-66.

4. Hantash BM, Renton B, Berkowitz RL, Stridde BC, Newman J. Pilot clinical study of a novel minimally invasive bipolar microneedle radiofrequency device. Lasers Surg Med 2009;41:87-95.

5. Lim SD, Yeo UC, Kim IH, Choi CW, Kim WS. Surgical corner. Evaluation of the wound healing response after deep dermal heating by fractional micro-needle radiofrequency device. J Drugs Dermatol 2013;12:1044-9.

6. Alexiades-Armenakas M, Rosenberg D, Renton B, Dover J, Arndt K. Blinded, randomized, quantitative grading comparison of minimally invasive, fractional radiofrequency and surgical face-lift to treat skin laxity. Arch Dermatol 2010;146:396-405.

7. Hruza G, Taub AF, Collier SL, Mulholland SR. Skin rejuvenation and wrinkle reduction using a fractional radiofrequency system. J Drugs Dermatol 2009:8:259-65.

8. el-Domyati M, el-Ammawi TS, Medhat W, Moawad O, Brennan D, Mahoney MG, et al. Radiofrequency facial rejuvenation: evidence-based effect. J Am Acad Dermatol 2011;64:524-35.

9. Alexiades-Armenakas M, Dover JS, Arndt KA. Unipolar versus bipolar radiofrequency treatment of rhytides and laxity using a mobile painless delivery method. Lasers Surg Med 2008;40:446-53.

10. Elsaie ML. Cutaneous remodeling and photorejuvenation using radiofrequency devices. Indian J Dermatol 2009;54:201-5.

11. Fisher GH, Jacobson LG, Bernstein LJ, Kim KH, Geronemus RG. Nonablative radiofrequency treatment of facial laxity. Dermatol Surg 2005;31:1237-41; discussion 1241.

12. Alster TS, Tanzi E. Improvement of neck and cheek laxity with a nonablative radiofrequency device: a lifting experience. Dermatol Surg 2004;30:503-7; discussion 507.
13. Nahm WK, Su TT, Rotunda AM, Moy RL. Objective changes in brow position, superior palpebral crease, peak angle of the eyebrow, and jowl surface area after volumetric radiofrequency treatments to half of the face. Dermatol Surg 2004;30:922-8; discussion 928.

14. Fritz M, Counters JT, Zelickson BD. Radiofrequency treatment for middle and lower face laxity. Arch Facial Plast Surg 2004;6: 370-3.

15. Biesman BS, Pope K. Monopolar radiofrequency treatment of the eyelids: a safety evaluation. Dermatol Surg 2007;33:794801.

16. Franco W, Kothare A, Ronan SJ, Grekin RC, McCalmont TH. Hyperthermic injury to adipocyte cells by selective heating of subcutaneous fat with a novel radiofrequency device: feasibility studies. Lasers Surg Med 2010;42:361-70.

17. Sukal SA, Geronemus RG. Thermage: the nonablative radiofrequency for rejuvenation. Clin Dermatol 2008;26:602-7.

18. Gabriel S, Lau RW, Gabriel C. The dielectric properties of biological tissues: III. Parametric models for the dielectric spectrum of tissues. Phys Med Biol 1996;41:2271-93.

19. Montesi G, Calvieri S, Balzani A, Gold MH. Bipolar radiofrequency in the treatment of dermatologic imperfections: clinicopathological and immunohistochemical aspects. J Drugs Dermatol 2007;6:890-6.

20. Cho SI, Chung BY, Choi MG, Baek JH, Cho HJ, Park CW, et al. Evaluation of the clinical efficacy of fractional radiofrequency microneedle treatment in acne scars and large facial pores. Dermatol Surg 2012;38:1017-24.

21. Seo KY, Kim DH, Lee SE, Yoon MS, Lee HJ. Skin rejuvenation by microneedle fractional radiofrequency and a human stem cell conditioned medium in Asian skin: a randomized controlled investigator blinded split-face study. J Cosmet Laser Ther 2013;15:25-33.

22. Gold MH, Biron JA. Treatment of acne scars by fractional bipolar radiofrequency energy. J Cosmet Laser Ther 2012;14:172-8.

23. Shin JU, Lee SH, Jung JY, Lee JH. A split-face comparison of a fractional microneedle radiofrequency device and fractional carbon dioxide laser therapy in acne patients. J Cosmet Laser Ther 2012;14:212-7.

24. Ryu HW, Kim SA, Jung HR, Ryoo MW, Lee KS, Cho JW. Clinical improvement of striae distensae in Korean patients using a combination of fractionated microneedle radiofrequency and fractional carbon dioxide laser. Dermatol Surg 2013;39:1452-8.

25. Kim IS, Park KY, Kim BJ, Kim MN, Kim CW, Kim SE. Efficacy of intradermal radiofrequency combined with autologous plateletrich plasma in striae distensae: a pilot study. Int J Dermatol 2012;51:1253-8.

26. Yang YJ, Lee GY. Treatment of striae distensae with nonablative fractional laser versus ablative $\mathrm{CO}(2)$ fractional laser: a randomized controlled trial. Ann Dermatol 2011;23:481-9. 